\title{
High-temperature mechanical properties of aluminium alloys reinforced with titanium diboride $\left(\mathrm{TiB}_{2}\right)$ particles
}

\author{
J. Oñoro \\ Ingeniería y Ciencia de los Materiales, ETSI Industriales, Universidad Politécnica de Madrid, c/José Gutiérrez Abascal, 2. 28006 Madrid, Spain
}

\begin{abstract}
The physical and mechanical properties of metal matrix composites were improved by the addition of reinforcements. The mechanical properties of particulate-reinforced metal-matrix composites based on aluminium alloys (6061 and 7015) at high temperatures were studied. Titanium diboride $\left(\mathrm{TiB}_{2}\right)$ particles were used as the reinforcement. All the composites were produced by hot extrusion. The tensile properties and fracture characteristics of these materials were investigated at room temperature and at high temperatures to determine their ultimate strength and strain to failure. The fracture surface was analysed by scanning electron microscopy. $\mathrm{TiB}_{2}$ particles provide high stability of the aluminium alloys (6061 and 7015) in the fabrication process. An improvement in the mechanical behaviour was achieved by adding $\mathrm{TiB}_{2}$ particles as reinforcement in both the aluminium alloys. Adding $\mathrm{TiB}_{2}$ particles reduces the ductility of the aluminium alloys but does not change the microscopic mode of failure, and the fracture surface exhibits a ductile appearance with dimples formed by coalescence.
\end{abstract}

Keywords: metal-matrix composites; aluminium; high-temperature properties; titanium diboride

\section{Introduction}

The production technology and use of composites have been improved significantly in recent decades. The physical and mechanical properties of metal-matrix composites (MMCs), such as high specific modulus and thermal stability, make them particularly attractive for application in the aerospace and automotive industries. MMCs are attractive engineering materials since they can be enhanced by selective reinforcement. Lightweight aluminium-matrix composites (AMCs) have been the focus of many studies on account of their outstanding properties. The powder metallurgy fabrication of AMCs generally gives good mechanical properties and is an inexpensive process. To obtain AMCs with optimal properties, a secondary processing of the composites, which ensures uniform distribution of the reinforcing material in the matrix and the formation of a good interfacial bond, is carried out. Among the various classic metal-forming procedures, extrusion has been most frequently used for the secondary processing operation because of its excellent preferential axial alignment and large compressive hydrostatic stress state [1]. One of the keys to the development and application of high-performance composite materials is the subtle tailoring of the matrix/reinforcement interface that must combine an efficient load transfer with the ability to arrest cracking. AMCs reinforced with hard ceramic particles are relatively easy to process and, in comparison with fibre-reinforced composites, are nearly isotropic. In addition, these AMCs exhibit high strength and stiffness, good creep resistance and superior wear resistance, whilst also provide good electrical and thermal conductivity. There is a general tendency to replace steels with lighter aluminium alloys and to develop aluminium alloys for use at higher temperatures. These circumstances make AMCs become strong candidates for wide applications in the automobile, aerospace, and military industries.

Extensive theoretical and experimental studies have been carried out on the fundamental relationships between the mechanical properties and the microstructure of AMCs with different types of matrix and either particles or fibres as the reinforcement [2-6]. The selection of the reinforcement type, geometry, and volume fraction is critical to obtaining the best combination of properties at a low cost [5]. The 6061 and 7015 aluminium alloys are used in the automotive industries (trucks and railroad cars), towers and structural applications, furniture, pipelines, canoes and other applications where strength, weldability, and corrosion resistance are needed. The particles used as reinforcement include nitrides, borides, carbides, and oxides [1-2].

Titanium diboride $\left(\mathrm{TiB}_{2}\right)$ is a ceramic material with rela- 
tively high strength, melting point $\left(2790^{\circ} \mathrm{C}\right)$, hardness and wear resistance [6]. Current use of this material, however, appears to be limited to special applications in some fields such as cutting tools, impact-resistant armour, crucibles, and wear-resistant coating. $\mathrm{TiB}_{2}$ particles do not react with aluminium, thereby avoiding the formation of brittle reaction products. $\mathrm{TiB}_{2}$ is an attractive strengthening agent for aluminium-based composites [6]. It could be an alternative to silicon carbide reinforcement in composites for which a high stiffness or a good wear resistance is a major requirement [7]. Various aspects of ceramic particle-reinforced AMCs have been investigated, especially in terms of the fabrication methods, interfacial characteristics, and mechanical properties [8-9]. To achieve the high performance required in the proposed applications, a good understanding of the high-temperature mechanical properties and the fracture behaviour of the AMCs at different temperatures is essential.

The mechanical properties at room and high temperatures of AMCs reinforced with ceramic particles have been widely studied. There are also many reports on the effects of volume fraction, size, shape, and orientation of the reinforcement on the fracture mechanisms and failure modes [10-11]. However, the few data were reported about the effects of $\mathrm{TiB}_{2}$ particles on reinforced AMCs at elevated temperatures. Thus, the purpose of this paper is to evaluate the effects of the temperature on the mechanical properties of 6061 and 7015 composites reinforced with $\mathrm{TiB}_{2}$ particles. The effect of the temperature on the behaviour of the fracture is also examined.

\section{Experimental}

Prealloyed aluminium alloy powders were produced by atomisation of the molten metal under argon. The matrix alloys were 6061 (Al-0.65Si- $0.87 \mathrm{Cu}-0.23 \mathrm{Cr},<0.2 \mathrm{Fe}$ ) and 7015 (Al-5.96Zn-0.63 Si-1.04Mg- $0.23 \mathrm{Cu}-0.21 \mathrm{Cr}-0.04 \mathrm{Fe})$. The particles were spherical in shape and less than $75 \mu \mathrm{m}$ in diameter. The diameters of the ceramic particles of $\mathrm{TiB}_{2}$ were in the range of 4 to $10 \mu \mathrm{m}$. The aluminium alloy powders, blended with $5 \mathrm{wt} . \% \mathrm{TiB}_{2}$, were mixed in a planetary ball mill. They were mechanically milled for $12 \mathrm{~min}$ at $150 \mathrm{r} / \mathrm{min}$ using chromium steel balls with a diameter of $20 \mathrm{~mm}$. The mechanical alloying was carried out in a water-cooled drum for $30 \mathrm{~min}$ at $500 \mathrm{r} / \mathrm{min}$ using chromium steel balls with a diameter of $6 \mathrm{~mm}$. Argon, at a flow rate of $100 \mathrm{~cm}^{3} / \mathrm{h}$, was used as the atmosphere during the milling.

The mixing powders were die-pressed at $200 \mathrm{MPa}$ in cylinders that were $25 \mathrm{~mm}$ in diameter. The cylinders were preheated at $150^{\circ} \mathrm{C}$ and protected with a graphite suspension in oil, which produced a thin film of graphite, heated to $500^{\circ} \mathrm{C}$ and extruded into bars of $10 \mathrm{~mm}$ diameter and ap- proximately $200 \mathrm{~mm}$ in length, followed by air cooling. The extrusion rate was $5: 2$ with an extrusion speed of $1 \mathrm{~mm} / \mathrm{s}$ and a maximum pressure of $400 \mathrm{MPa}$. The bars were heat treated. The 7015 matrix bars were heated at $515^{\circ} \mathrm{C}$ for 30 min under an argon atmosphere and then water quenched and aged at $120^{\circ} \mathrm{C}$ for $6 \mathrm{~h}$. The 6061 matrix bars were heated at $530^{\circ} \mathrm{C}$ for $1 \mathrm{~h}$ under a $\mathrm{N}_{2}-5 \% \mathrm{H}_{2}$ atmosphere and then water quenched and aged at $175^{\circ} \mathrm{C}$ for $8 \mathrm{~h}$. All the samples fabricated by this route presented a homogeneous distribution of titanium borides in the surrounding matrix (Figs. 1 and 2). Bars of the 6061 and 7015 alloys without reinforced particles were obtained and tested as reference materials.

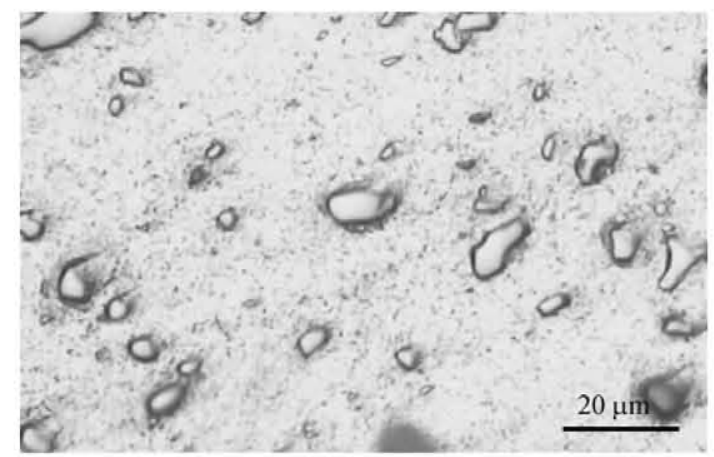

Fig. 1. Microstructure of $\mathrm{TiB}_{2}$ particles in the $6061 \mathrm{AMC}$.

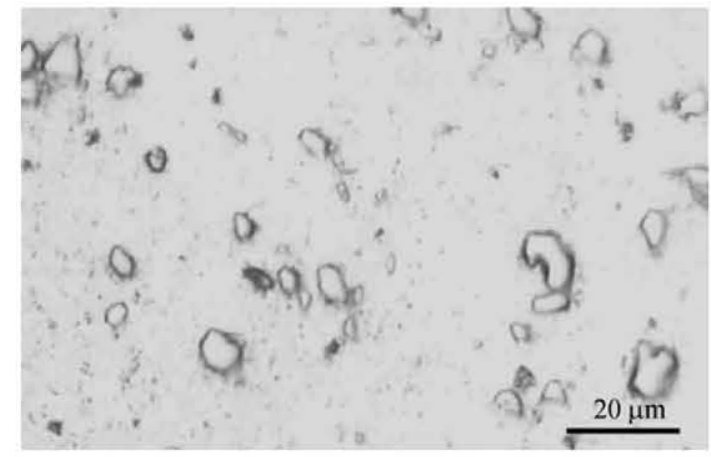

Fig. 2. Microstructure of $\mathrm{TiB}_{2}$ particles in the $7015 \mathrm{AMC}$.

The hardness measurements were carried out using a Vickers diamond pyramid indenter at $3 \mathrm{~N}$ load for $15 \mathrm{~s}$. These measurements were realised on transverse sections of extruded bars. The reported values were the average of five measurements. The tensile strength was measured on machined extruded bars according to the ISO 2740 Standard. Tensile samples were polished with 1000 grit grinding SiC paper in order to reduce the machining scratches and thus decrease the influence of surface defects on the tensile behaviour of the sample. The tensile tests at room and elevated temperatures were performed on a structural test machine (Instron: Model 1362) equipped with a $20 \mathrm{kN}$ load cell. The tests were carried out at a crosshead speed of $2 \mathrm{~mm} / \mathrm{min}$. Specimens were held at the test temperature for $10 \mathrm{~min}$ prior 
to testing. The ultimate strength and elongation were obtained by the method given in the EN 10002 Standard. Microstructures and fracture characterisations of the broken samples were observed using optical and scanning electron microscopy (SEM) at magnifications of 250 to 1000 . Particular attention was paid to examining for evidence of the cracking and decohesion of $\mathrm{TiB}_{2}$, and the influence of the microstructure on the fracture morphology.

\section{Results and discussion}

Optical microscopy and SEM showed relatively uniform distributions of $\mathrm{TiB}_{2}$ in the reinforced samples with no areas substantially depleted of $\mathrm{TiB}_{2}$ in either alloy 6061 or alloy 7015, as shown in Figs. 1 and 2. The spacing between the $\mathrm{TiB}_{2}$ particles varies from 0 to $30 \mu \mathrm{m}$, with an average of about $14 \mu \mathrm{m}$. The mean grain diameter is $12 \mu \mathrm{m}$ in the 6061 aluminium alloy and $10 \mu \mathrm{m}$ in the 6061 AMCs. However, the mean grain size diameter is $8 \mu \mathrm{m}$ in the 7015 aluminium alloy and $7 \mu \mathrm{m}$ in the $7015 \mathrm{AMCs}$. $\mathrm{TiB}_{2}$ does not react with aluminium. Thus, after solution heat treatments, no evidence of reaction products was observed in the samples. In AMCs, the problem is complicated because most of the matrix/reinforcement couples that are of mechanical interest are out-of-equilibrium systems [12].

The hardness results at room temperature are summarised in Table 1. The results are the mean values based on three tests. $\mathrm{TiB}_{2}$ produces an important increase in hardness in reinforced materials from 80 to $130 \mathrm{HV}$ for the 6061 aluminium matrix alloy and a slight increase from 138 to $154 \mathrm{HV}$ for the 7015 aluminium matrix alloy. The reinforced particles were randomly dispersed, as shown in Figs. 1 and 2, so the higher increase in hardness of the 6061 aluminium matrix alloy can be attributed to the initially soft matrix, where the reinforced particles produce a major effect, but the final value of the hardness is lower than that of the 7015 aluminium matrix.

Table 1. Hardness test results

\begin{tabular}{ccccc}
\hline Material & 6061 & $\mathrm{TiB}_{2} / 6061 \mathrm{AMCs}$ & 7015 & $\mathrm{TiB}_{2} / 7015 \mathrm{AMCs}$ \\
\hline $\mathrm{HV}_{3 \mathrm{~N}}$ & 80 & 126 & 138 & 148 \\
\hline
\end{tabular}

The relationships of ultimate tensile strength vs. the temperature are shown in Fig. 3. The results are the mean values based on duplicate tests. The 7015 matrix aluminium alloy is stronger, with and without $\mathrm{TiB}_{2}$-reinforced particles, at every temperature. The AMCs 7015 are stronger than the 7015 aluminium alloy, but the difference reduces as the temperature increases, so at $500^{\circ} \mathrm{C}$ the tensile properties are quite close. The 6061 matrix alloy behaves similarly but has lower values.
Fig. 3 shows that all the materials studied behave similarly when the temperature increases. The tensile properties reduce as expected, but the process is not uniform, because several metallurgical phenomena are involved simultaneously. The reduction in mechanical properties is small when the temperature is below $200^{\circ} \mathrm{C}$. In the region of $200-300^{\circ} \mathrm{C}$, the tensile properties reduce very quickly because the matrix alloys lose the aging heat treatment by growing coherent hardened precipitates into larger incoherent phases with a consequent matrix softening. At $300-400^{\circ} \mathrm{C}$, the mechanical properties of the 7015 matrix alloy reduce more quickly than those of the 6061 alloy, so their values are quite close. The solid solution hardening produced by the higher concentration and number of alloy elements in the 7015 matrix loses importance, and the strength is reduced to the values close to those of the 6061 matrix alloy. At $400-500^{\circ} \mathrm{C}$, the reduction in tensile strength is not very important because the values are very low for all the tested materials.

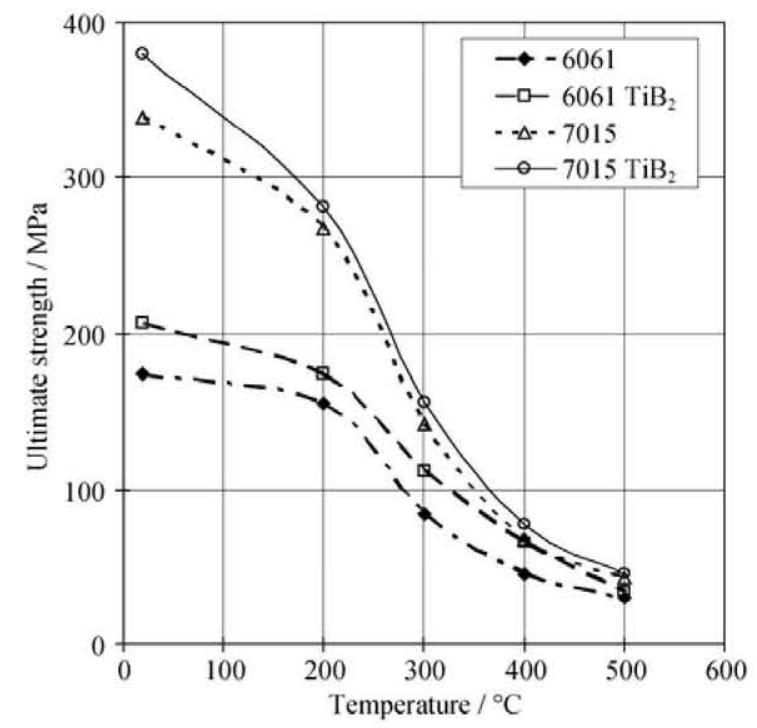

Fig. 3. Relations of ultimate strength vs. temperature of the sintered AMCs and the aluminium alloys.

The $\mathrm{TiB}_{2}$ particles increased the mechanical properties of both matrix alloys over the entire temperature interval that was analysed. This effect was reduced at high temperatures but is still significant to $500^{\circ} \mathrm{C}$. The presence of $\mathrm{TiB}_{2}$ particles caused the mean grain size of both aluminium alloys to be slightly reduced. However, the mean grain size was originally very small and the presence of reinforcement particles did not produce significant grain refinement. Consequently, the grain refinement of the AMCs obtained is not sufficient to produce a significant improvement of the mechanical properties. The $\mathrm{TiB}_{2}$ particles improve the mechanical properties mainly by stress transference from the aluminium matrix to the reinforced particles. The interaction between the dislocations and particles results in an increase 
in strength, which is associated with the Orowan mechanism by which a dislocation bypasses impenetrable obstacles, where a dislocation bows out considerably to leave a dislocation loop around a particle, or the Hirsch mechanism that leaves a prismatic loop behind a particle [13]. The elastic modulus and strength of the $\mathrm{TiB}_{2}$ did not change significantly within the temperature interval analysed, but the aluminium matrix softens and the mobility of the dislocations increases with the temperature increasing by a climbing mechanism.

Macroscopic observations of the fracture surface were undertaken to identify the fracture process and mode as a function of temperature. Figs. 4 and 5 show the fractures of the sintered 6061 aluminium alloy and the 6061 AMCs samples tested at different temperatures up to $500^{\circ} \mathrm{C}$. The sintered 6061 aluminium alloy shows fracture surfaces with ductile macroscopic fracture characteristics. At low temperature, the failure occurs along a plane inclined at an angle of about $45^{\circ}$ to the tension axis, which is a typical shear-face tensile fracture in ductile materials in thin sections (i.e., under plane stress conditions). When the test temperature increases the ductility increases, the mode of failure changes to the classic cup-and-cone fracture. The failure occurs as a result of an appreciable plastic deformation. At high temperatures, the samples experience considerable deformation and necking before failure (Fig. 4). Both processes are characteristic of macroscopic ductile fracture. The strain-to-failure and the reduction-in-area of the 6061 alloy increase as the temperature rises. This behaviour is consistent with the observed degradation in strength at high test temperatures. At room temperature, the 6061 AMCs show a fracture surface where the failure occurs along a plane inclined at an angle of about $45^{\circ}$ to the tension axis, which is characteristic of macroscopic ductile fracture. When the test temperature increases the surface of fracture changes up to $400^{\circ} \mathrm{C}$, the reduction in cross-sectional area increases, and the failure occurs along a plane at $90^{\circ}$ to the tension axis; the fracture tries to change to the cup-and-cone fracture, with very small shear zone (Fig. 6). The addition of $\mathrm{TiB}_{2}$ particles to the 6061 aluminium alloy produces a change in the deformation and failure processes, with an important reduction in ductility and necking mainly at high temperatures. These changes are consistent with the increases in the mechanical properties of hardness and tensile strength. The $\mathrm{TiB}_{2}$ particles are non-shearable barriers against dislocation movement in the matrix. Therefore, the dislocation movement is strongly affected by the $\mathrm{TiB}_{2}$ particles under the conditions tested. The plastic constraint effect through reinforcement of the matrix induces a state of high triaxial stress in the alloy matrix, which reduces the ductility and necking of the 6061 AMCs to lower values compared with the 6061 aluminium alloy. At high temperatures, the ductility and necking of the 6061 aluminium alloy is very large (Fig. 4). However, the 6061 AMCs present a lower ductility and the samples exhibit fracture with low necking.

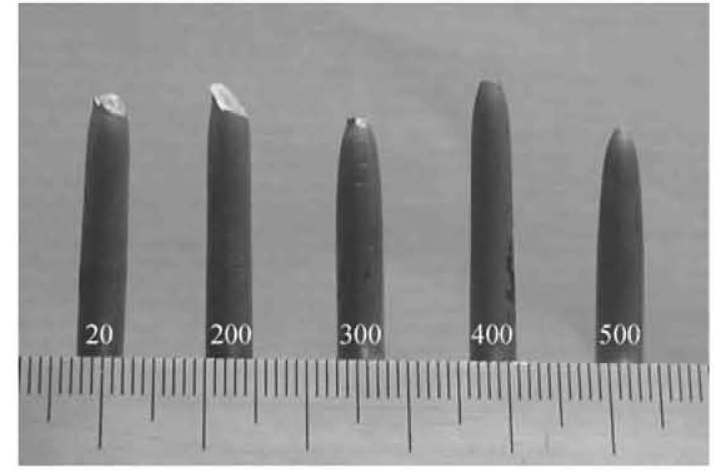

Fig. 4. Fracture morphologies of the sintered 6061 aluminium alloy samples tested at $20,200,300,400$, and $500^{\circ} \mathrm{C}$.

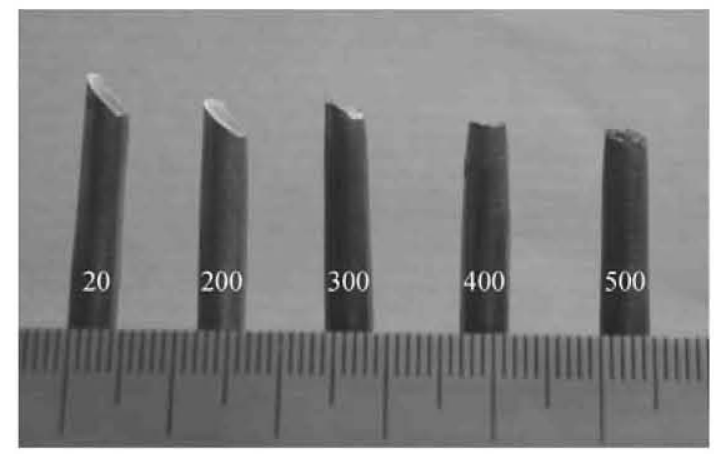

Fig. 5. Fracture morphologies of the sintered $\mathrm{TiB}_{2}$ particlereinforced $6061 \mathrm{AMC}$ samples tested at $20,200,300,400$, and $500^{\circ} \mathrm{C}$.

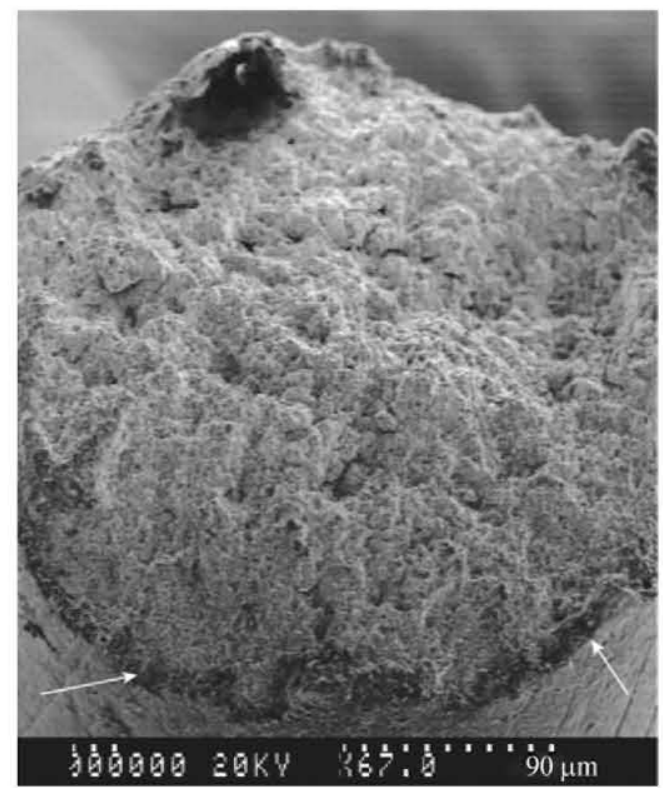

Fig. 6. Fracture surface of the sintered $6061 \mathrm{AMC}$ with $\mathrm{TiB}_{2}$ particles, showing cup-and-cone fracture with small external shear zones at $400^{\circ} \mathrm{C}$ (white arrows). 
Figs. 7 and 8 show the fractures of the sintered 7015 aluminium alloy and 7015 AMCs samples tested at different temperatures up to $500^{\circ} \mathrm{C}$. The fracture morphology of both materials was quite similar, the ductility and necking of the samples increase with temperature. At room temperature, both materials show brittle fracture macroscopic characteristics. As the temperature increases, the ductility also increases, although it increases faster for the 7015 aluminium alloy, as shown by the $200^{\circ} \mathrm{C}$ test in Fig. 7, which presents the ductile fracture characteristics, whilst the 7015 AMCs present brittle fracture characteristics at the same temperature. At $300^{\circ} \mathrm{C}$ and higher temperatures, the fracture morphologies are not very different, as the mechanical properties of both the materials are very close at $300^{\circ} \mathrm{C}$ and higher temperatures.

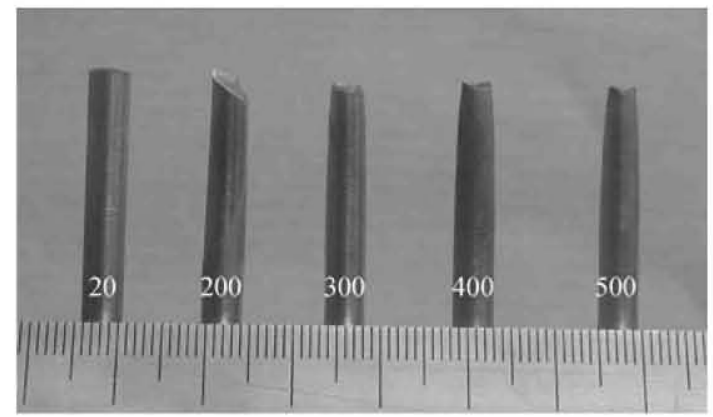

Fig. 7. Fracture morphologies of the sintered 7015 aluminium alloy samples tested at $20,200,300,400$, and $500^{\circ} \mathrm{C}$.

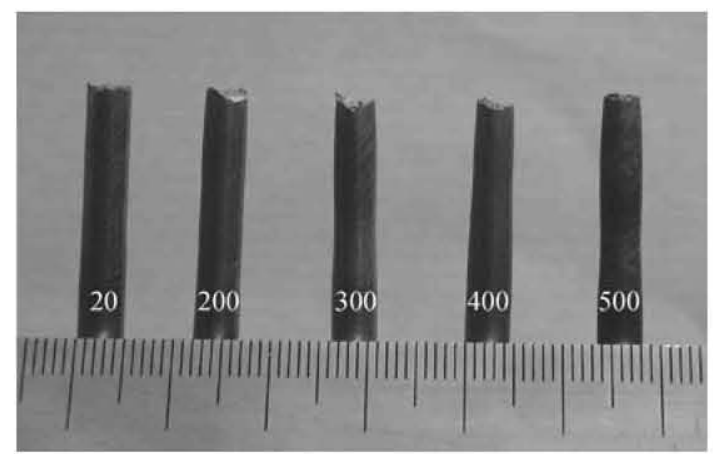

Fig. 8. Fracture morphologies of the sintered $\mathrm{TiB}_{2}$ particlereiforced $7015 \mathrm{AMC}$ samples tested at 20, 200, 300, 400, and $500^{\circ} \mathrm{C}$.

The basic mechanism of composite deformation is the load transfer from the matrix to the reinforcement [13]. A good bonding between the matrix and the reinforced particles gives rise to better load transfer and improved properties. The tensile loading leads to high tensile stresses at the particle/matrix interface. Figs. 9 and 10 show a scanning electron fractograph of the fracture surface of the AMCs tested at 20 and $400^{\circ} \mathrm{C}$. At all the temperatures at which they were tested microscopically, the AMCs fracture surfaces exhibited a ductile appearance (dimples). The dimples are

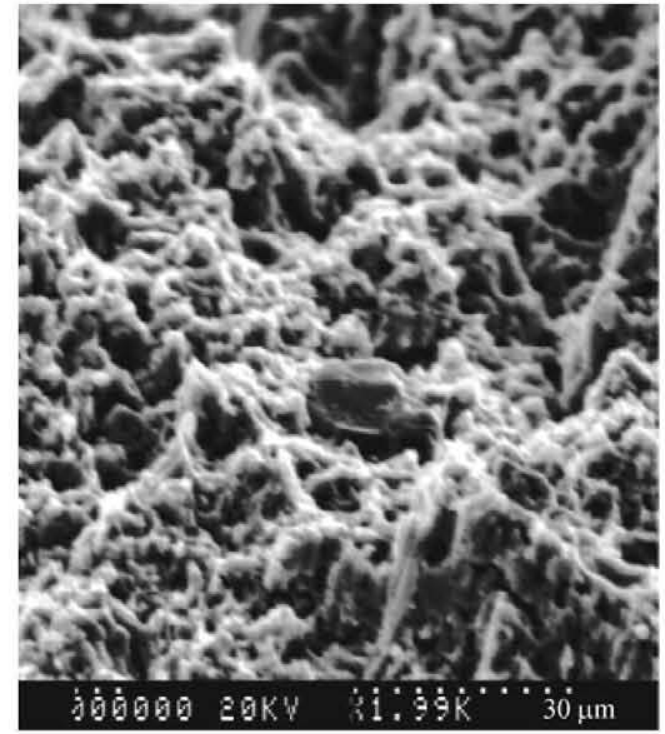

Fig. 9. Dimples morphologies on the fracture surface of the sintered $7015 \mathrm{AMC}$ with $\mathrm{TiB}_{2}$ particles at $20^{\circ} \mathrm{C}$.

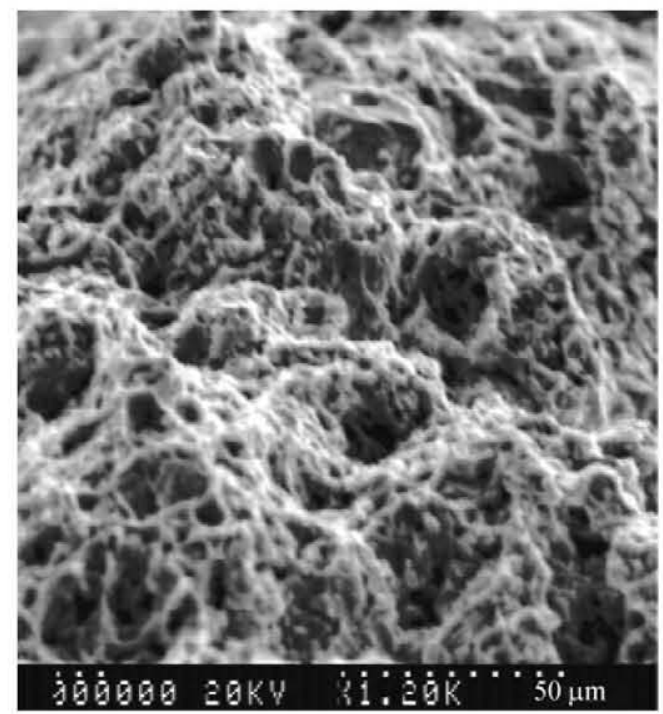

Fig. 10. Dimples morphologies on the fracture surface of the sintered $6061 \mathrm{AMC}$ with $\mathrm{TiB}_{2}$ particles at $400^{\circ} \mathrm{C}$.

formed as a result of the localised damage at high strain levels by particle-matrix decohesion. The coalescence of micro-voids leads to crack propagation and the final fracture of the composite material, and the micro-voids can be clearly distinguished in Figs. 9 and 10. The amount of ductile fracture increases as the temperature increases in both the AMCs, which is associated with the increased dimple density (Fig. 10). The mean dimple size in the fracture surface of reinforced alloys is similar to the $\mathrm{TiB}_{2}$ particle dimension $(8 \mu \mathrm{m})$ at low and high temperatures (Figs. 9 and 10). In contrast, smaller dimples were observed under SEM in the 6061 and 7015 alloys $(2 \mu \mathrm{m})$.

$\mathrm{TiB}_{2}$ particles reduce the ductility of the $6061 \mathrm{AMCs}$, and the mode of failure changes at high temperature from high 
deformation and necking cup-and-cone fracture for the 6061 aluminium alloy to low deformation without necking cupand-cone fracture for the 6061 AMCs. The SEM image of shear-face fracture of the 6061 aluminium alloy exhibits shallow dimples that form by the joining of micro-voids by shear along slip bands (Fig. 11), unlike the cup-and-cone fracture, which exhibits deep conical dimples formed by coalescence. At room temperature, the 6061 AMCs show macroscopic brittle fracture, but the fracture surface exhibits a ductile appearance. The $\mathrm{TiB}_{2}$-reinforced particles reduce the ductility but do not change the microscopic mode of failure.

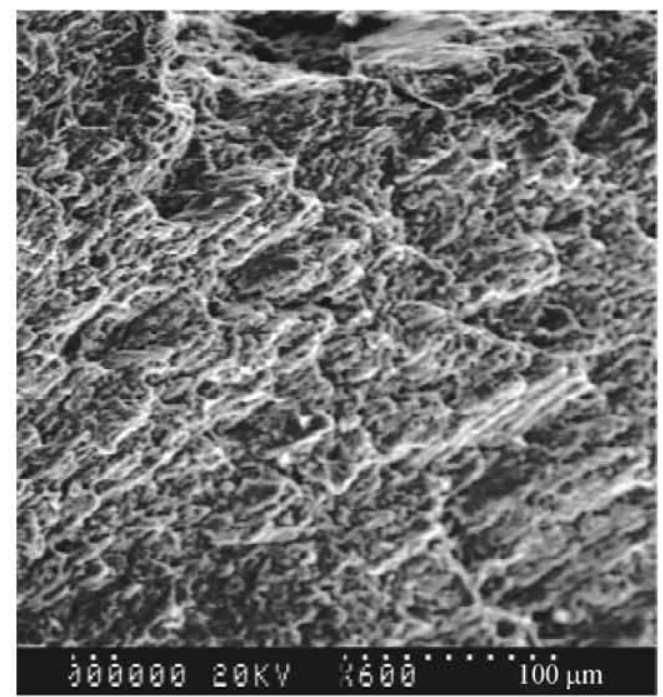

Fig. 11. Dimple morphologies on the fracture surface of the sintered 6061 aluminium alloy at $400^{\circ} \mathrm{C}$.

The AMCs present a homogeneous distribution of $\mathrm{TiB}_{2}$ particles in the matrix. Figs. 9 and 10 show a high degree of adhesion between the $\mathrm{TiB}_{2}$ particles and the aluminium matrix. Extensive matrix plastic flow around the particles is evident and indicative of strong interfacial bonding between the $\mathrm{TiB}_{2}$ particles and the aluminium alloy matrix. $\mathrm{The}^{\mathrm{TiB}} \mathrm{B}_{2}$ particles provide high stability for the aluminium alloy matrices in the fabrication process, heat treatment and sample testing. Figs. 9 and 10 show that the process of micro-void formation and coalescence involves considerable localised plastic deformation and requires the expenditure of a large amount of energy.

\section{Conclusions}

The tensile strength, elongation and fracture characteristics of AMCs at a high temperature were studied. The sintered 6061 and 7015 aluminium alloys were reinforced with $\mathrm{TiB}_{2}$ particles. Uniaxial, monotonic tensile tests were carried out at room temperature and at high temperatures (up to $500^{\circ} \mathrm{C}$ ).

$\mathrm{TiB}_{2}$ particles provide high stability of the aluminium
6061 and 7015 matrices in the fabrication process, heat treatments, and the temperature testing that were considered. An improvement in the mechanical behaviour was achieved by adding $\mathrm{TiB}_{2}$ particles as reinforcement in both the matrix alloys. The tensile strengths of the $\mathrm{AMCs}$ with $\mathrm{TiB}_{2}$, and the aluminium 6061 and 7015 matrix alloys without reinforcing, decreased as the temperature increased. The ductility, quantified in terms of elongation-to-failure and reduction-in-area, increased as the test temperature increased.

Macroscopic observations of AMCs at room temperature reveal the fracture surface to be brittle, but the microscopic features are reminiscent of locally ductile materials (voids and dimples).

\section{References}

[1] Ghosh A.K., Fundamentals of Metal-Matrix Composites, Butterworth, London, 1993: 43.

[2] Prabu S.B. and Karunamoorthy L., Microstructure-based finite element analysis of failure prediction in particle-reinforced metal-matrix-composite, J. Mater. Process. Technol., 2008, 207 (1-3): 53.

[3] Peng J., Li W., Huang F., Tian J., Liu G., and Du J., Microstructure evolution of rare earth Pr modified alumina-silicate short fiber-reinforced $\mathrm{Al}-\mathrm{Si}$ metal matrix composites, Rare Met., 2009, 28: 164

[4] Deng C., Zhang X., Ma Y., and Wang D., Fabrication of aluminum matrix composite reinforced with carbon nanotubes, Rare Met., 2007, 26 (5): 450.

[5] Hunt W.H., Discontinuously-reinforced aluminum: the second generation, [in] Processing and Fabrication of Advanced Materials III, TMS, Warrendale, PA, 1994: 663.

[6] Munro R.G., Material properties of titanium diboride, J. Res. Natl. Inst. Stand. Technol., 2000, 105: 709.

[7] Kumar S., Chakraborty M., Sarma V.S., and Murty B.S., Tensile and wear behaviour of in situ $\mathrm{Al}-7 \mathrm{Si} / \mathrm{TiB}_{2}$ particulate composites, Wear, 2008, 265: 134.

[8] Lloyd D.J., Particle reinforced $\mathrm{Al}$ and $\mathrm{Mg}$ matrix composites, Int. Mater. Rev., 1994, 39 (1): 1.

[9] Del Rio E., Nash J.M., Williams J.C., Breslin M.C., and Daehn G.S., Co-continuous composites for high-temperature applications, Mater. Sci. Eng. A, 2007, 463: 115.

[10] Smagorinski M.E., Tsantrizos P.G., Grenier S., Cavasin A., Brzezinski T., and Kim G., The properties and microstructure of Al-based composites reinforced with ceramic particles, Mater. Sci. Eng. A, 1998, 244: 86.

[11] Arsenault R.J., Fishman S., and Taya M., Deformation and fracture behavior of metal-ceramic matrix composite materials, Prog. Mater. Sci., 1994, 38 (1): 1.

[12] Ernst F., Metal-oxide interfaces, Mater. Sci. Eng., 1995, 14 (3): 97.

[13] Hatano T., Dynamics of a dislocation bypassing an impenetrable precipitate: the Hirsch mechanism revisited, Phys. Rev. B, 2006, 74 (2): art. No.020102. 